\title{
Innovation and safety in critical care: should we collaborate with the industry? Pro
}

\author{
Anthony C. Gordon ${ }^{1,2^{*}}$ (D) and James A. Russell ${ }^{3,4}$
}

(c) 2018 Springer-Verlag GmbH Germany, part of Springer Nature and ESICM

As clinicians we all want to improve care for our patients. We can do that in two ways. We can do what we currently do better, or we can do new things (better). The development of large clinical academic trials groups and networks has enabled clinicians to understand what particular clinical care leads to better patient-centred outcomes. Ironically, we have learnt that many of our "usual" interventions either provided no benefit or were even harmful. Thus, clinicians, can improve the safety and effectiveness of critical care practice. But when it comes to innovation-new therapeutics and novel diagnostics-then it is hard to imagine that we could achieve this without input from or partnership with industry. Furthermore, a brief walk around an ICU illustrates cogently the vast number of devices used and drugs being infused, all of which originated in industry, some with much and some with little clinician scientist input. We argue herein that such collaboration is not only acceptable, it is also necessary and can be done ethically, using established guidelines and conflict of interest disclosure.

Sceptics point out that there have been few new therapeutics in routine critical care despite industry's repeated attempts in recent decades. But that does not mean that we should abandon working with industry. One indeed might argue that more thought-leader and bedside clinician input is needed in the discovery (selecting targets) and validation (better trial design using better

\footnotetext{
*Correspondence: anthony.gordon@imperial.ac.uk

1 Section of Anaesthetics, Pain Medicine and Intensive Care, Department of Surgery and Cancer, Imperial College London, London, UK Full author information is available at the end of the article

For contrasting viewpoints, please go to https://doi.org/10.1007/s0013 4-018-5295-5

The views expressed are those of the author(s) and not necessarily those of the NHS, the NIHR or the Department of Health.
}

patient-centred outcomes) stages. In other medical specialties, innovations from industry have revolutionised patient management and improved outcomes. HIV care and outcomes were completely changed within a generation because of multi-drug antiretroviral therapy that was developed in conjunction with industry [1]. Immune checkpoint inhibitors and other immunotherapies are now transforming oncology. If we want similar success in critical care then we argue that it is vital that we collaborate with industry to strengthen the underpinning science and later clinical development.

It is frequently reported that industry-sponsored research is more likely to publish positive findings from clinical trials than academically sponsored trials [2]. The reasons for this are likely multi-factorial. Certainly, the plethora of industry-sponsored "me-too" drug and device trials where new interventions are shown to be noninferior to current drugs and devices minimally advances care. The requirement for prospective trial registration should mitigate delayed or selective publication of unfavourable results. We contend that academic collaborators in industry-led research should push industry to continue to improve in this area.

We and others suggest that the chances of more positive trials could increase by using better methodology. The competitive market place requires stringent criteria for industry to select only the most promising early stage agents to progress to the really expensive stage-clinical development. The subsequent trials methodology must be strong. Some studies report industry collaboration trials were more likely to use high-quality methods than trials without industry funding [3]. Other reports found limited but important differences; industry studies were more likely to be at low risk of bias because of blinding but more likely to yield conclusions that did not align with the results compared with non-industry studies [2]. 
Of course, there need to be appropriate checks and balance. There are always concerns about the risk of bias when money is involved but there are plenty of other sources of bias that may be as, if not more, important [4]. There are well-established and evolving guidelines for ethical conduct of academics with industry regarding disclosure of conflicts of interest such as the Sunshine Act in the USA requiring industry to disclose annually its payments to physicians [5]. Any agreements between academia and industry, including payments both directly to the individual and to their institution (which may play a valuable role in supporting an academic laboratory), should be disclosed so that reviewers and readers can evaluate possible bias. Although payments direct to physicians have a clear potential to be a conflict of interest, payments to institutions also have this potential and so should be declared too. Robust contracts ensure that the highest standards of research are maintained, including publishing protocols and analytical plans prospectively and agreeing that all results will be made public in a timely fashion, regardless of the study outcome. Rules over intellectual property must be agreed in advance. Fortunately, there are well-established principles [e.g., Lambert agreement used by the UK Medical Research Council (MRC)] that standardise template contracts to unify university-industry research collaborations.

Although harder to quantify, academic bias is now recognised as another potential source of bias to be considered. Requirements to publish and bring in grant income to academic institutions are still key measures to achieve promotion and tenure. It is still easier to publish positive results in high-impact journals and secure the next big grant based on positive results of previous work. It can be argued that a lifelong tenured academic position is probably worth more in financial terms than a short-term industry collaboration.

The benefits of industry-academic collaborations are recognised by major medical grant-giving bodies that have joint industry-academic grant schemes (e.g., UK NIHR Invention for Innovation fund [6], Wellcome Trust's Health Innovation Challenge Fund [7], EU Innovative Medicines Initiative [8]). Relevant to critical care is the recent Experimental Medicine Initiative to Explore New Therapies (EMINENT) network supported by the UK MRC and with matched support from GSK that provides unique access to a portfolio of experimental drug compounds [9]. Academic researchers from five universities will work with industry partners to better understand the mechanisms of inflammatory and fibrotic lung disease to then develop new treatments.

As critical care understands how genomics influences patient outcomes and response to treatment [10], collaborations such as the Structural Genomics Consortium will be key to drive innovative research in this area [11]. This not-for-profit organisation, with multiple academic and industry partners, provides an open collaborative network so that its research is available to the scientific community with no strings attached.

The benefits of such public-private collaborations are recognised by governments throughout the world. The recent UK Life Sciences: industrial strategy points out that innovation is key to improving outcomes for patients but also lays out the case for public investment in biomedical and health research to improve outcomes and to deliver strong economic growth [12]. We as clinical academics must drive this agenda for the health of our patients as well as the wealth of our nations.

If clinician-scientists and clinicians choose not to collaborate and consult with industry, then industry will push ahead without us. Industry employs clinicians, but many will have given up clinical work some years ago and so can be out of touch with current clinical practice. Accordingly, we need the best practising clinicians to help guide research development. Although industry's fundamental objective is to generate profit for its shareholders, if it develops effective treatments then two complementary objectives can be achieved-better outcomes for patients and increased revenue for industry. Again, the HIV story illustrates this paradigm.

Clinical scientists will continue to innovate but if we want to translate this into improved patient care we need industry collaboration. A good example comes from this journal recently, where academic investigators demonstrated that cell surface markers predict risk of subsequent infection (INFECT study [13]). Collaboration with industry was an essential ingredient to conduct this multi-centre study, to provide standardised assays across all sites over time and to allow appropriate and meaningful analysis, interpretation and publication.

In conclusion, there are undoubtedly exciting innovations around the corner for critical care, including rapid pathogen detection, -omic technologies to stratify and personalise patient care $[14,15]$, artificial intelligence to aid diagnoses and treatment decisions [16], new immunostimulation [17] and stem cell therapies [18]. To think that we as clinical academics can develop these on a large scale, on our own, is naïve and we should therefore actively collaborate with our industry colleagues to robustly test them and make them a reality for our patients.

\section{Author details}

${ }^{1}$ Section of Anaesthetics, Pain Medicine and Intensive Care, Department of Surgery and Cancer, Imperial College London, London, UK. ${ }^{2}$ Intensive Care 
Unit, Imperial College Healthcare NHS Trust, St Mary's Hospital, London, UK. ${ }^{3}$ Centre for Heart Lung Innovation (HLI), Vancouver, Canada. ${ }^{4}$ Division of Critical Care Medicine, St. Paul's Hospital, University of British Columbia, 1081 Burrard Street, Vancouver, BC V6Z 1Y6, Canada.

\section{Acknowledgements}

ACG is funded by a National Institute of Health Research (NIHR) Research Professorship award (RP-2015-06-018) and supported the NIHR Comprehensive Biomedical Research Centre based at Imperial College Healthcare NHS Trust and Imperial College London.

\section{Compliance with ethical standards}

\section{Conflicts of interest}

ACG: reports that he has received speaker fees from Orion Corporation Orion Pharma and Amomed Pharma. He has consulted for Ferring Pharmaceuticals, Tenax Therapeutics, Baxter Healthcare, Bristol-Myers Squibb and GSK and received grant support from Orion Corporation Orion Pharma, Tenax Therapeutics and HCA International with funds paid to his institution. JAR (last 36 months): Dr. Russell reports patents owned by the University of British Columbia (UBC) related to PCSK9 inhibitor(s) and sepsis and related to the use of vasopressin in septic shock. Dr. Russell is an inventor on these patents. Dr. Russell is a founder, Director and shareholder in Cyon Therapeutics Inc. [developing a sepsis therapy (PCSK9 inhibitor)]. Dr. Russell has share options in Leading Biosciences Inc. Dr. Russell is a shareholder in Molecular You Corp. Dr. Russell reports receiving consulting fees in the last 3 years from: (1) Asahi Kesai Pharmaceuticals of America (AKPA) (developing recombinant thrombomodulin in sepsis); (2) La Jolla Pharmaceuticals (developing angiotensin II; Dr. Russell chaired the DSMB of a trial of angiotensin II from 2015 to 2017) — no longer actively consulting; (3) Ferring Pharmaceuticals (manufactures vasopressin and was developing selepressin)—no longer actively consulting; (4) Cubist Pharmaceuticals (now owned by Merck; formerly was Trius Pharmaceuticals; developing antibiotics)—no longer actively consulting; (5) Leading Biosciences (was developing a sepsis therapeutic that is no longer in development) —no longer actively consulting; (6) Grifols (sells albumin)—no longer actively consulting; (7) CytoVale Inc. (developing a sepsis diagnostic)—no longer actively consulting. Dr. Russell reports having received an investigatorinitiated grant from Grifols (entitled "Is HBP a mechanism of albumin's efficacy in human septic shock?") that is provided to and administered by UBC

Received: 21 June 2018 Accepted: 4 July 2018

Published online: 8 November 2018

\section{References}

1. Lima VD, Lourenco L, Yip B, Hogg RS, Phillips P, Montaner JS (2015) AIDS incidence and AIDS-related mortality in British Columbia, Canada, between 1981 and 2013: a retrospective study. Lancet HIV 2:e92-e97
2. Lundh A, Lexchin J, Mintzes B, Schroll JB, Bero L (2017) Industry sponsorship and research outcome. Cochrane Database Syst Rev 2:MR000033

3. Linker A, Yang A, Roper N, Whitaker E, Korenstein D (2017) Impact of industry collaboration on randomised controlled trials in oncology. Eur J Cancer 72:71-77

4. Rosenbaum L (2015) Understanding bias-the case for careful study. N Engl J Med 372:1959-1963

5. Chimonas S, DeVito NJ, Rothman DJ (2017) Bringing transparency to medicine: exploring physicians'views and experiences of the Sunshine Act. Am J Bioeth 17:4-18

6. https://www.nihr.ac.uk/funding-and-support/funding-for-research-studi es/funding-programmes/invention-for-innovation/. Accessed 18 July 2018

7. https://wellcome.ac.uk/what-we-do/directories/health-innovation-chall enge-fund-projects-funded. Accessed 18 July 2018

8. https://www.imi.europa.eu/. Accessed 18 July 2018

9. https://mrc.ukri.org/news/browse/mrc-gsk-and-five-leading-uk-universiti es-collaborate-to-crack-difficult-disease-areas/. Accessed 18 July 2018

10. Rautanen A, Mills TC, Gordon AC, Hutton P, Steffens M, Nuamah R, Chiche JD, Parks T, Chapman SJ, Davenport EE, Elliott KS, Bion J, Lichtner P, Meitinger T, Wienker TF, Caulfield MJ, Mein C, Bloos F, Bobek I, Cotogni P, Sramek V, Sarapuu S, Kobilay M, Ranieri VM, Rello J, Sirgo G, Weiss YG Russwurm S, Schneider EM, Reinhart K, Holloway PA, Knight JC, Garrard CS, Russell JA, Walley KR, Stuber F, Hill AV, Hinds CJ, EEG Investigators (2015) Genome-wide association study of survival from sepsis due to pneumonia: an observational cohort study. Lancet Respir Med 3:53-60

11. https://www.thesgc.org/. Accessed 18 July 2018

12. Bell J (2017) Life sciences: industrial strategy

13. Conway-Morris A, Wilson J, Shankar-Hari M (2018) Immune activation in sepsis. Crit Care Clin 34:29-42

14. Davenport EE, Burnham KL, Radhakrishnan J, Humburg P, Hutton P, Mills TC, Rautanen A, Gordon AC, Garrard C, Hill AV, Hinds CJ, Knight JC (2016) Genomic landscape of the individual host response and outcomes in sepsis: a prospective cohort study. Lancet Respir Med 4:259-271

15. Russell JA, Spronk P, Walley KR (2018) Using multiple'omics strategies for novel therapies in sepsis. Intensive Care Med 44:509-511

16. Komorowski M, Celi LA, Badawi O, Gordon AC, Faisal AA (2018) The intensive care Al clinician learns optimal treatment strategies for sepsis. Nat Med. https://doi.org/10.1038/s41591-018-0213-5

17. Francois $B$, Jeannet R, Daix T, Walton AH, Shotwell MS, Unsinger J, Monneret G, Rimmele T, Blood T, Morre M, Gregoire A, Mayo GA, Blood J, Durum SK, Sherwood ER, Hotchkiss RS (2018) Interleukin-7 restores lymphocytes in septic shock: the IRIS-7 randomized clinical trial. JCI Insight 3:e98960

18. McIntyre LA, Stewart DJ, Mei SHJ, Courtman D, Watpool I, Granton J, Marshall J, Dos Santos C, Walley KR, Winston BW, Schlosser K, Fergusson DA, Canadian Critical Care Trials G, Canadian Critical Care Translational Biology G (2018) Cellular immunotherapy for septic shock. A phase I clinical trial. Am J Respir Crit Care Med 197:337-347 